Article

\title{
A New Computational Model of Step Gauge Calibration Based on the Synthesis Technology of Multi-Path Laser Interferometers
}

\author{
Guoying Ren ${ }^{1,2, * \mathbb{D}}$, Xinghua $Q u^{1}$ and Xiangjun Chen ${ }^{1}$ \\ 1 State Key Laboratory of Precision Measurement Technology and Instruments, Tianjin University, \\ Tianjin 300072, China; quxinghua@tju.edu.cn (X.Q.); jun689074@163.com (X.C.) \\ 2 Length Division, National Institute of Metrology, Beijing 100029, China \\ * Correspondence: rengy@nim.ac.cn
}

Received: 20 February 2020; Accepted: 17 March 2020; Published: 19 March 2020 updates

Featured Application: Inspired by the principle of closed-loop vector model, this paper proposes a new computational model to realize the high precision calibration of the step gauge based on the commercial CMM platform and laser interference technology. According to this method, only real-time measurements of the attitude and displacement changes in the movement of the step gauge are needed for the accurate length value of the step gauge to be obtained.

\begin{abstract}
A step gauge is a commonly used length standard for international comparison, and its calibration accuracy is often used as a sign to measure a country's length Calibration and Measurement Capability (CMC). Based on this, some developed countries and developing countries all over the world have been carrying out the research of precision calibration technology for step gauge. On the basis of summarizing the current situation of step gauge calibration technology in other countries, this paper presents a new computational model of step gauge calibration based on the Synthesis Technology of Multi-Path Laser Interferometers (SMLI) and an auto-collimator, which can synthesize the three laser light paths into the measured centerline of step gauge. It is very important to obtain a good measurement accuracy for the step gauge, conformed to the Abbe principle, no matter where it is installed on the CMM measurement platform. In this paper, the development of the mathematical model, the data collection algorithms, data analysis techniques, and measurement uncertainty budgets are discussed. Finally, the experimental measurement is carried out and the measurement accuracy is verified to be effective. The results show that this method can effectively avoid the influence of Abbe error in length measurement, and significantly enhance the calibration accuracy of the step gauge.
\end{abstract}

Keywords: metrology; step gauge; length calibration; multi-path laser synthesis technology

\section{Introduction}

As a universal length standard for calibrating instruments, step gauges are widely used in the precision calibration and error compensation of high-precision instruments, such as the Coordinate Measuring Machine (CMM), numerical control machine tool, optical instruments and so on.

Moreover, the International Bureau of Metrology (BIPM) has also listed the step gauge as a key length comparison, making it an important component in measuring the metrological capacity of a national geometric measurement calibration laboratory [1-4]. Many ambitious countries have established their own step gauge calibration devices [5-7].

On the basis of Leitz CMM, the National Metrology Institute of Japan (NMIJ) realize their step gauge calibration by use of the large displacement measurement of a laser interference measuring 
system, and the micro displacement of the probe of the CMM, thereby obtaining the dimension values of the measured step gauge. The measurement uncertainty of this device is $U=(0.06+0.22 \mathrm{~L}) \mu \mathrm{m}$ [8].

Based on the Moore M48 CMM, the National Institute of Standards and Technology (NIST) has developed a step gauge calibration device using a specially designed induction type probe that provides a short-term repeatability of $7 \mathrm{~nm}$ [9].

The above two calibration systems are based on the measurement platform of CMM, but the Abbe error, pitch and yaw errors are considered only as the error sources of measurement uncertainty, rather than being directly measured and compensated.

The National Institute of Metrology of Finland (VTT MIKES) has constructed a step gauge calibration system on a vibration isolated stone table with a 1D movable guide rail, rather than CMM, to eliminate mechanical disturbances [10]. The measurement uncertainty of the system is $U=Q[0.090$; $0.14 \mathrm{~L}] \mu \mathrm{m}$. This system also considers the pitch and yaw errors as the error sources of measurement uncertainty, and so does not directly measure them.

At Physikalisch-Technische Bundesanstalt (PTB), the Nanometer Comparator is upgraded with a tactile sensor system to add the capability to measure step gauges. The $1 \sigma$ repeatability of the device is better than $7 \mathrm{~nm}$ [11]. The system adopts the precise displacement measurement method based on the principle of vacuum interference, which has high precision, but is relatively complex.

Based on the analysis of the advantages and disadvantages of the above-mentioned instruments, this paper proposes a new computational model of step gauge calibration based on the Synthesis Technology of Multi-Path Laser Interferometers (SMLI), in which three of four interferometers are used for distance measurement, and the fourth channel is used for the wavelength compensation of the laser [12-14], thereby establishing our own step gauge calibration device on the platform of Leitz CMM. By adding four laser interferometers in the measurement platform, the spatial position relationship model of three out of four lasers is constructed, and the synthetic optical path of these lasers is translated to the measurement line of the measured step gauge, which can effectively eliminate the influence of the Abbe error of the CMM on the measurement result, and compensate the errors of pitch and yaw. Based on the presented calculation model of the closed-loop vector principle, the error caused by pitch and yaw can be corrected to the measured length in real time by measuring attitude change with an auto-collimator to obtain a better calibration accuracy.

This paper will firstly introduce the composition and structure of the developed step gauge measurement system by in detail. Then, the principle and implementation of the measurement method are be addressed systematically. Finally, the experimental results are given and discussed to provide a conclusion.

\section{The Mathematical Modeling and Simulation}

In order to eliminate the Abbe measurement error, we designed a mathematical model of SMLI which can synthesize the three laser light paths into the one measured center line of the step gauge, as shown in Figure 1. The $P_{1}, P_{2}$ and $P_{3}$ are the installation points of three reflector mirrors, and the $\mathrm{O}$ is the measurement point of the step gauge. The three reflector mirrors and the step gauge are installed in the same moveable platform. The $\overline{\mathrm{P}_{1} \mathrm{P}_{1}^{\prime}}$ is the first laser measurement path during the measurement that is marked as $l_{1} u_{1}\left(l_{1}\right.$ is the measurement value of the first interferometer, and $u_{1}$ is its unit directional vector), the $\overline{\mathrm{P}_{2} \mathrm{P}_{2}^{\prime}}$ is the second laser measurement path that is marked as $l_{2} u_{2}\left(l_{2}\right.$ is the measurement value of the second interferometer, and $u_{2}$ is its unit directional vector), the $\overline{\mathrm{P}_{3} \mathrm{P}_{3}^{\prime}}$ is the third laser measurement path that is marked as $l_{3} u_{3}\left(l_{3}\right.$ is the measurement value of the third interferometer, and $u_{3}$ is its unit directional vector), and the $\overline{\mathrm{OO}^{\prime}}$ (the $\mathrm{O}$ point is the first measurement position and the $\mathrm{O}^{\prime}$ is the nth measurement position) is the synthesized measurement path of the measured step gauge that is marked as $r$ ( $r$ is the only unknown quantity). The $\beta_{i}$ is the angle between the direction of $\mathrm{OPi}$ and $\mathrm{X}$ axis of coordinate system, which is known and definite. The $\theta_{\mathrm{i}}$ is the angle between the direction of $\mathrm{PiPi}^{\prime}(\mathrm{i}=1,2,3)$ and the $\mathrm{Z}$ axis of the coordinate system, which represents the change of pitch angle and yaw angle during the measurement and is measured by the auto-collimator. 


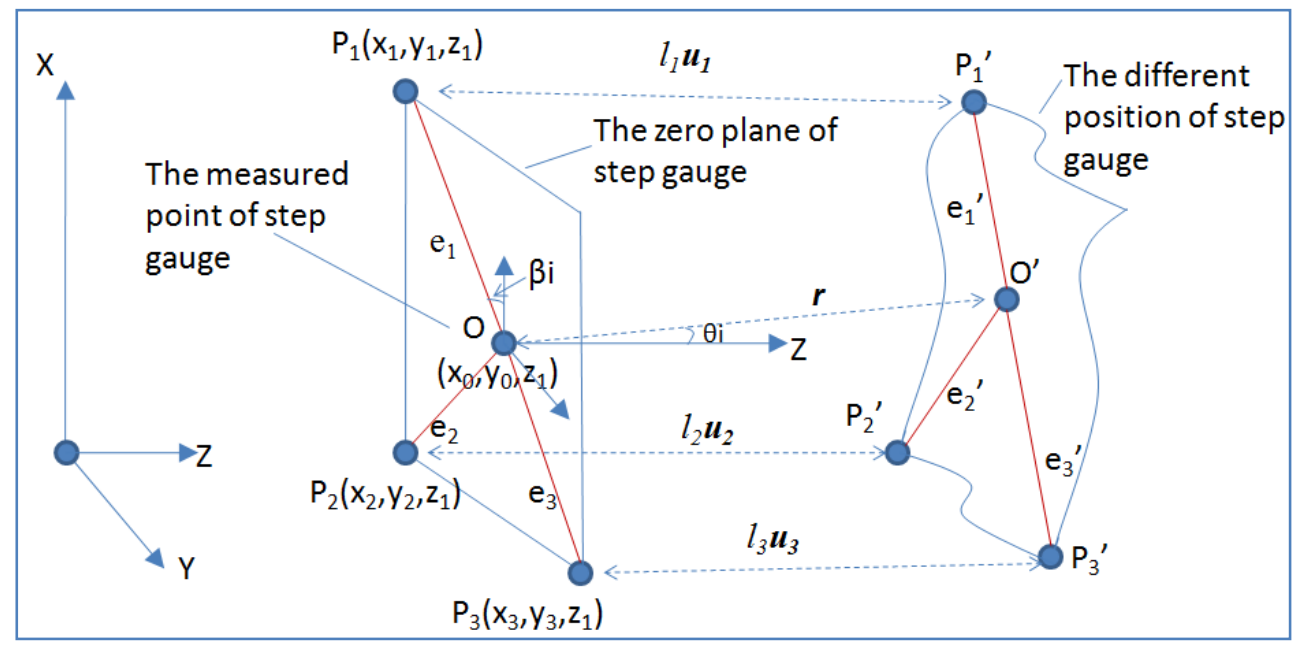

Figure 1. Mathematical model of Synthesis Technology of Multi-Path Laser Interferometers (SMLI).

According to Figure 1, the mathematical model based on the closed-loop vector principle [15-17] is as follows.

$$
\overrightarrow{\boldsymbol{r}}=\overrightarrow{\boldsymbol{e}}_{i}+l_{i} \overrightarrow{\boldsymbol{u}}_{i}-\overrightarrow{\boldsymbol{e}}_{i}, i=1,2,3,
$$

where $\overrightarrow{\boldsymbol{e}_{i}}=e_{i}\left(\begin{array}{lll}\cos \beta_{i} & \sin \beta_{i} & 0\end{array}\right)^{T}(i=1,2,3),\|\overrightarrow{O P}\|_{i}=\left\|\overrightarrow{\boldsymbol{e}_{i}}\right\|$, it is known.

where $\overrightarrow{\boldsymbol{u}_{i}}=\left(\sin \theta_{i} \cos \beta_{i} \sin \theta_{i} \sin \beta_{i} \cos \theta_{i}\right)^{T}$,it is known. Then, $l_{\mathrm{i}}$ is also known.

Changing Equation (1) to Equation (2):

$$
\left(\boldsymbol{r}-\boldsymbol{e}_{i}-l_{i} \boldsymbol{u}_{i}\right)^{T}\left(\boldsymbol{r}-\boldsymbol{e}_{i}-l_{i} \boldsymbol{u}_{i}\right)=e_{i}^{2} .
$$

Expanding Equation (2) to Equation (3) is done as follows.

$$
\left[\left(\boldsymbol{r}-\boldsymbol{e}_{i}\right)^{T}-\left(l_{i} \boldsymbol{u}_{i}\right)^{T}\right]\left[\left(\boldsymbol{r}-\boldsymbol{e}_{i}\right)-\left(l_{i} \boldsymbol{u}_{i}\right)\right]-e_{i}^{2}=0 .
$$

Then, Equation (3) is expanded as follows.

$$
\begin{aligned}
& \Rightarrow\left(\boldsymbol{r}-\boldsymbol{e}_{i}\right)^{T}\left(\boldsymbol{r}-\boldsymbol{e}_{i}\right)-\left(\boldsymbol{r}-\boldsymbol{e}_{i}\right)^{T}\left(l_{i} \boldsymbol{u}_{i}\right)-\left(l_{i} \boldsymbol{u}_{i}\right)^{T}\left(\boldsymbol{r}-\boldsymbol{e}_{i}\right)+l_{i}^{2}-e_{i}^{2}=0, \\
& \Rightarrow\left(\boldsymbol{r}-\boldsymbol{e}_{i}\right)^{T}\left(\boldsymbol{r}-\boldsymbol{e}_{i}\right)+l_{i}^{2}-e_{i}^{2}-\left(\boldsymbol{r}-\boldsymbol{e}_{i}\right)^{T}\left(l_{i} \boldsymbol{u}_{i}\right)-\left(l_{i} \boldsymbol{u}_{i}\right)^{T}\left(\boldsymbol{r}-\boldsymbol{e}_{i}\right)=0 .
\end{aligned}
$$

Suppose the coordinate of point $\mathrm{O}$ is $(0,0,0)$, and the coordinate of point $\mathrm{O}^{\prime}$ is $(x, y, z)$, then:

$$
G_{i}-l_{i} \boldsymbol{r}^{T} \boldsymbol{u}_{i}+l_{i} \boldsymbol{e}_{i}^{T} \boldsymbol{u}_{i}-l_{i} \boldsymbol{u}_{i}^{T} \boldsymbol{r}+l_{i} \boldsymbol{u}_{i}^{T} \boldsymbol{e}_{i}=0,
$$


where:

$$
\begin{aligned}
& G_{i}=\left(\boldsymbol{r}-\boldsymbol{e}_{i}\right)^{T}\left(\boldsymbol{r}-\boldsymbol{e}_{i}\right)+l_{i}^{2}-e_{i}^{2}=\boldsymbol{r}^{T} \boldsymbol{r}-\boldsymbol{r}^{T} \boldsymbol{e}_{i}-\boldsymbol{e}_{i}^{T} \boldsymbol{r}+\boldsymbol{e}_{i}^{T} \boldsymbol{e}_{i}+l_{i}^{2}-e_{i}^{2} \\
& =x^{2}+y^{2}+z^{2}-\left(\begin{array}{lll}
x & y & z
\end{array}\right)\left(\begin{array}{l}
e_{i} \cos \beta_{i} \\
e_{i} \sin \beta_{i} \\
0
\end{array}\right)-\left(\begin{array}{lll}
e_{i} \cos \beta_{i} & e_{i} \sin \beta_{i} & 0
\end{array}\right)\left(\begin{array}{l}
x \\
y \\
z
\end{array}\right)+e_{i}^{2}+l_{i}^{2}-e_{i}^{2} \\
& =x^{2}+y^{2}+z^{2}-2 x e_{i} \cos \beta_{i}-2 y e_{i} \sin \beta_{i}+l_{i}^{2} \\
& l_{i} \boldsymbol{r}^{T} \boldsymbol{u}_{i}=l_{i}\left(\begin{array}{lll}
x & y & z
\end{array}\right)\left(\begin{array}{lll}
\sin \theta_{i} \cos \beta & \sin \theta_{i} \sin \beta_{i} & \cos \theta
\end{array}\right)^{T} \\
& =l_{i}\left(x \sin \theta_{i} \cos \beta_{i}+y \sin \theta_{i} \sin \beta_{i}+z \cos \theta_{i}\right) \\
& l_{i} \boldsymbol{e}_{i}^{T} \boldsymbol{u}_{i}=1_{i}\left(\begin{array}{lll}
e_{i} \cos \beta_{i} & e_{i} \sin \beta_{i} & 0
\end{array}\right)\left(\begin{array}{lll}
\sin \theta_{i} \cos \beta_{i} & \sin \theta_{i} \sin \beta_{i} & \cos \theta_{i}
\end{array}\right)^{T} \\
& =l_{i}\left(e_{i} \sin \theta_{i} \cos ^{2} \beta_{i}+e_{i} \sin \theta_{i} \sin ^{2} \beta_{i}\right) \\
& =e_{i} l_{i} \sin \theta_{i} \\
& l_{i} \boldsymbol{u}_{i}^{T} \boldsymbol{r}=l_{i}\left(\begin{array}{lll}
\sin \theta_{i} \cos \beta_{i} & \sin \theta_{i} \sin \beta_{i} & \cos \theta_{i}
\end{array}\right)\left(\begin{array}{lll}
x & y & z
\end{array}\right)^{T} \\
& =l_{i}\left(x \sin \theta_{i} \cos \beta_{i}+y \sin \theta_{i} \sin \beta_{i}+z \cos \theta_{i}\right) \\
& l_{i} \boldsymbol{u}_{i}^{T} \boldsymbol{e}_{i}=l_{i}\left(\begin{array}{llll}
\sin \theta_{i} \cos \beta_{i} & \sin \theta_{i} \sin \beta_{i} & \cos \theta_{i}
\end{array}\right)\left(\begin{array}{lll}
e_{i} \cos \beta_{i} & e_{i} \sin \beta_{i} & 0
\end{array}\right)^{T} \\
& =l_{i}\left(e_{i} \sin \theta_{i} \cos ^{2} \beta_{i}+e_{i} \sin \theta_{i} \sin ^{2} \beta_{i}\right) \\
& =e_{i} l_{i} \sin \theta_{i}
\end{aligned}
$$

Then, Equation (4) can be extended to Equation (5).

$$
x^{2}+y^{2}+z^{2}-2 x e_{i} \cos \beta_{i}-2 y e_{i} \sin \beta_{i}+l_{i}^{2}-2 l_{i}\left(x \cos \beta_{i}+y \sin \beta_{i}-e_{i}\right) \sin \theta_{i}-2 l_{i} z \cos \theta_{i}=0
$$

Considering that Equation (5) is the function of $(x, y, z)$, we can get Equation (6):

$f_{i}(x, y, z)=x^{2}+y^{2}+z^{2}+l_{i}^{2}-2\left(l_{i} \sin \theta_{i}+e_{i}\right) \cos \beta_{i} x-2\left(l_{i} \sin \theta_{i}+e_{i}\right) \sin \beta_{i} y+2 l_{i} e_{i} \sin \theta_{i}-2 l_{i} z \cos \theta_{i}=0$.

Let $\mathrm{t}=(\mathrm{x} y \mathrm{z}), \mathrm{t}(\mathrm{k})$ is the $\mathrm{k}$-th approximation of the solution $\mathrm{t}, f_{\mathrm{i}}(\mathrm{t})$ is expanded in vector form by Taylor series to Equation (7).

$$
f_{i}(t) \approx f_{i}\left(t^{(k)}\right)+\nabla f_{i}\left(t^{(k)}\right)^{T}\left(t-t^{(k)}\right)
$$

that is:

$$
\dot{f}(t)=\left(\begin{array}{c}
\nabla f_{1}(t)^{T} \\
\nabla f_{2}(t)^{T} \\
\vdots \\
\nabla f_{n}(t)^{T}
\end{array}\right)=\left(\begin{array}{cccc}
\frac{\partial f_{1}(t)}{\partial t_{1}} & \frac{\partial f_{1}(t)}{\partial t_{2}} & \ldots & \frac{\partial f_{1}(t)}{\partial t_{n}} \\
\frac{\partial f_{2}(t)}{\partial t_{1}} & \frac{\partial f_{2}(t)}{\partial t_{2}} & \cdots & \frac{\partial f_{2}(t)}{\partial t_{n}} \\
\vdots & \vdots & \ldots & \vdots \\
\frac{\partial f_{m}(t)}{\partial t_{1}} & \frac{\partial f_{m}(t)}{\partial t_{2}} & \cdots & \frac{\partial f_{m}(t)}{\partial t_{n}}
\end{array}\right) .
$$

By using the Newton iterative method to solve the formula, the solution $t$ can easily be calculated: $t^{(k+1)}=t^{(k)}+\Delta t^{(k)}$.

The procedure of the MATLAB simulation is as follows.

(1) The initial values of coordinate point $t_{0}=\left(\begin{array}{lll}x_{0} & y_{0} & z_{0}\end{array}\right)^{T}$ are assigned for the Newton iterative method;

(2) Calculate the initial value of the function according to the initial value $t_{0}$;

(3) Calculating the initial Hesse matrix $\dot{f}_{0}(t)$;

(4) According to the formula $f^{\prime}\left(t^{(k)}\right) \Delta t^{(k)}=-f\left(t^{(k)}\right)$, the value $\Delta t^{(0)}$ can be calculated;

(5) According to the formula $t^{(k+1)}=t^{(k)}+\Delta t^{(k)}$, the value $t^{(1)}$ can be obtained;

(6) Judge whether the end condition of the iteration is met. If not, return to step (2) to continue iteration.

In order to verify the accuracy of the mathematical model, according to the actual operation state and the actual situation of the measuring device, we design two sets of the angles $\theta, \theta \in\left[-2^{\circ}, 0^{\circ}\right]$ 
and $\theta \in\left[0^{\circ}, 2^{\circ}\right]$ respectively, and generate the deflection angle according to the interval of $0.5^{\circ}$. The simulation results are shown in Figure 2.

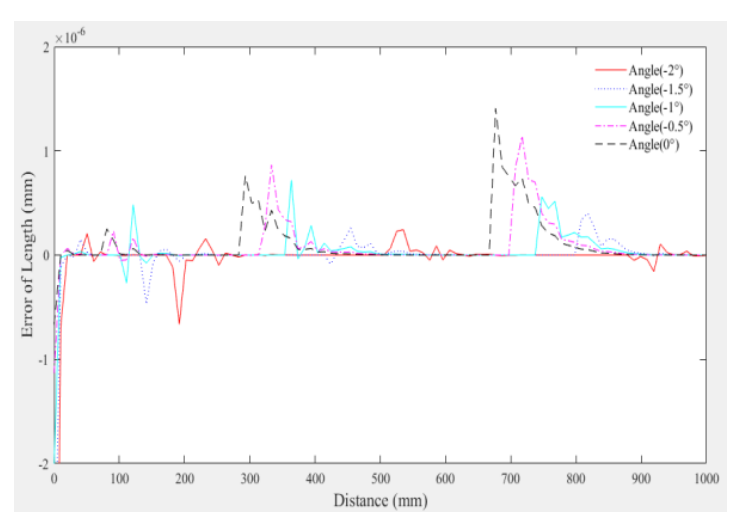

(a)

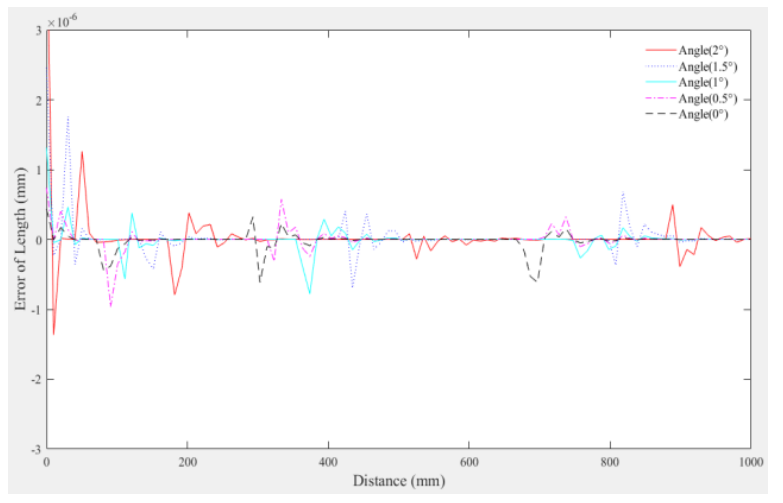

(b)

Figure 2. Simulation distribution of measurement length deviation of different distances of step gauge with different attitude angle $\theta$; (a). $\theta$ is a negative angle, which means the normal direction of the measured surface and the starting zero plane of the step gauge is opposite; (b) when $\theta$ is a positive angle, the normal direction of the measured surface and the starting zero plane of the step gauge are the same.

It can be seen from Figure 2 that the maximum length error of the simulation results is less than $3 \mathrm{~nm}$.

\section{Device and Experiment}

According to the above-mentioned mathematical model, the step gauge calibration system is developed, as shown in Figure 3.

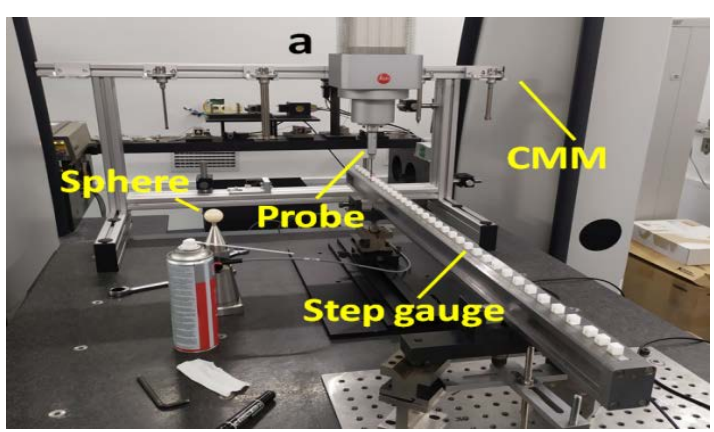

(a)

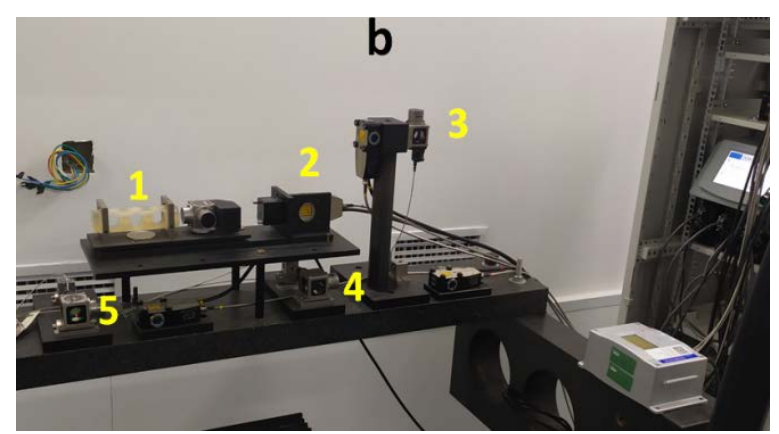

(b)

Figure 3. The step gauge measurement system; (a) actual calibration scenario of step gauge measurement system; (b) the critical optical system. Among this, 1 is the refractive index tracker to compensate the laser wavelength change, 2 is the plane interferometer, 3, 4 and 5 are the three-way length measuring interferometers from a single-frequency laser.

The trigger signal of the probe of CMM is used to determine the position of the measuring surface of the step gauge.

Before the experiment, it is necessary to calibrate the trigger accuracy of CMM probe. In this system, we adopt the trigger probe with a parallel leaf spring structure, and the displacement change of the probe can be measured by a Linear Variable Differential Transformer (LVDT).

The measuring principle of the probe is shown in Figure 4. Given the $U_{\text {prim }}$ signal at the input end of LVDT, when the probe moves to the left side, it drives the core to move to the left, which 
leads to the greater voltage $U_{\text {left }}$ in the left than the voltage $U_{\text {right }}$ in the right, so the output voltage $\mathrm{U}_{\text {sec }}$ is displayed as a sinusoidal positive signal; otherwise, it is a sinusoidal negative signal. After shaping, subdividing and amplifying the output voltage $U_{\text {sec, }}$, it is converted into digital voltage signal via an 18-bit analog-to-digital conversion(AD) card first, and then converted into the moved displacement value.

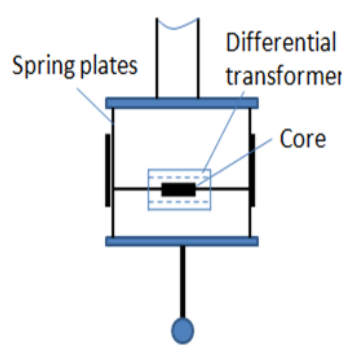

(a)

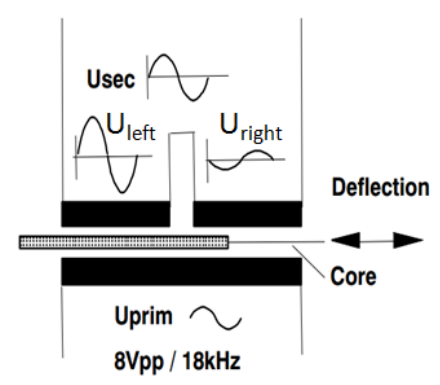

(b)

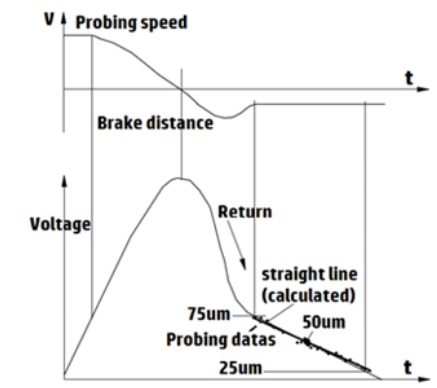

(c)

Figure 4. Measuring principle diagram of precision displacement probe for Coordinate Measuring Machine (CMM). (a) Mechanical schematic diagram of the CMM probe; (b) circuit schematic diagram of the CMM probe; (c) schematic diagram of the voltage of the probe signal changing with time during the contact measurement of the probe.

In this system, the trigger sampling interval of the probe is in the linear region of the falling edge of the probe voltage signal shown in Figure 4c.

The key technology of the step gauge measurement system in realizing the high measurement accuracy is to realize the synchronous sampling and signal synthesis of the probe voltage signal of the $\mathrm{CMM}$ and the displacement measurement data of the laser interferometer. The probe of CMM produces the voltage signal with linear change in the measurement process, as shown in Figure 5a. Through synchronous dynamic sampling, the corresponding laser interferometer displacement measurement signal is obtained, as shown in Figure 5b. After the two signals are synthesized, the constant coordinates of the measuring points at the time of triggering are obtained, as shown in Figure 5c.

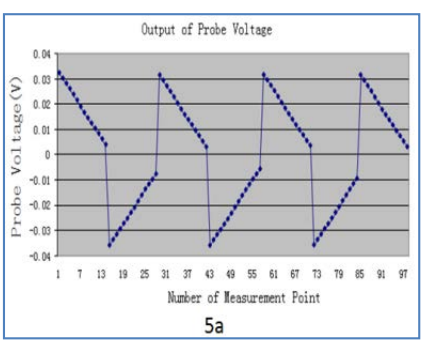

(a)

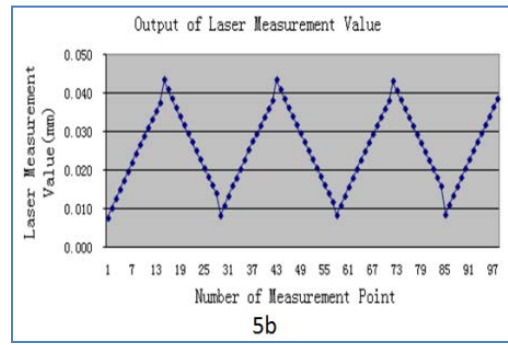

(b)

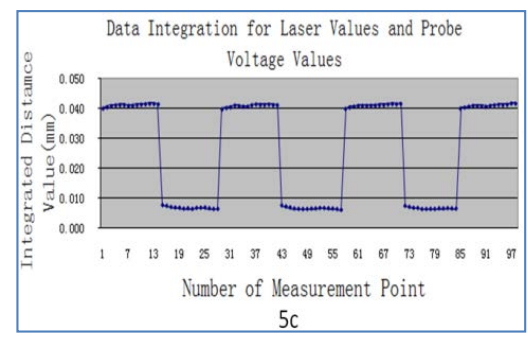

(c)

Figure 5. Signal synthetic diagram of probe voltage and displacement of laser interferometer: (a) the sampled voltage value via AD card after triggering during measurement; (b) the sampled laser value after triggering; (c) the combined value of laser value and voltage value obtained by synchronous sampling after triggering.

Before calibration, we first use the known high-level standard ball (its sphericity is $0.03 \mu \mathrm{m}$, its diameter is $29.98604 \mathrm{~mm}$ ) to calibrate the diameter of the CMM probe. The two-side measurement points of the standard ball are measured 10 times, and the measurement results are shown in Table 1 below. 
Table 1. The measurement results for calibrate the diameter of the CMM probe.

\begin{tabular}{ccc}
\hline $\begin{array}{c}\text { Measurement } \\
\text { Number }\end{array}$ & \multicolumn{2}{c}{ The Measured Laser Value(mm) } \\
\cline { 2 - 3 } & left side & right side \\
\hline 1 & 713.81023 & 678.82778 \\
\hline 2 & 713.81020 & 678.82771 \\
\hline 3 & 713.81024 & 678.82777 \\
\hline 4 & 713.81029 & 678.82778 \\
\hline 5 & 713.81028 & 678.82775 \\
\hline 6 & 713.81026 & 678.82778 \\
\hline 7 & 713.81031 & 678.82779 \\
\hline 8 & 713.81024 & 678.82773 \\
\hline 9 & 713.81023 & 678.82773 \\
\hline 10 & 713.81030 & 678.82777 \\
\hline Std. Deviation & 0.000034 & 0.000026 \\
\hline Average Value & 713.81026 & 678.82776 \\
\hline
\end{tabular}

Then, the calibrated diameter of the probe can be calculated by Equation (8).

$$
D_{\text {probe }}=L_{\text {leftLaser }}-R_{\text {rightLaser }}-D_{\text {sphereNom. }}=713.81026-678.82776-29.98604=4.99646 \mathrm{~mm} .
$$

In order to verify the correctness of the mathematic model and this device, a step gauge made by the KOBA company of Germany is calibrated. The maximum deviation of measurement results between this device and the Deutscher Kalibrierdienst (DKD) device is less than $0.5 \mu \mathrm{m}$, as shown in Figure 6.

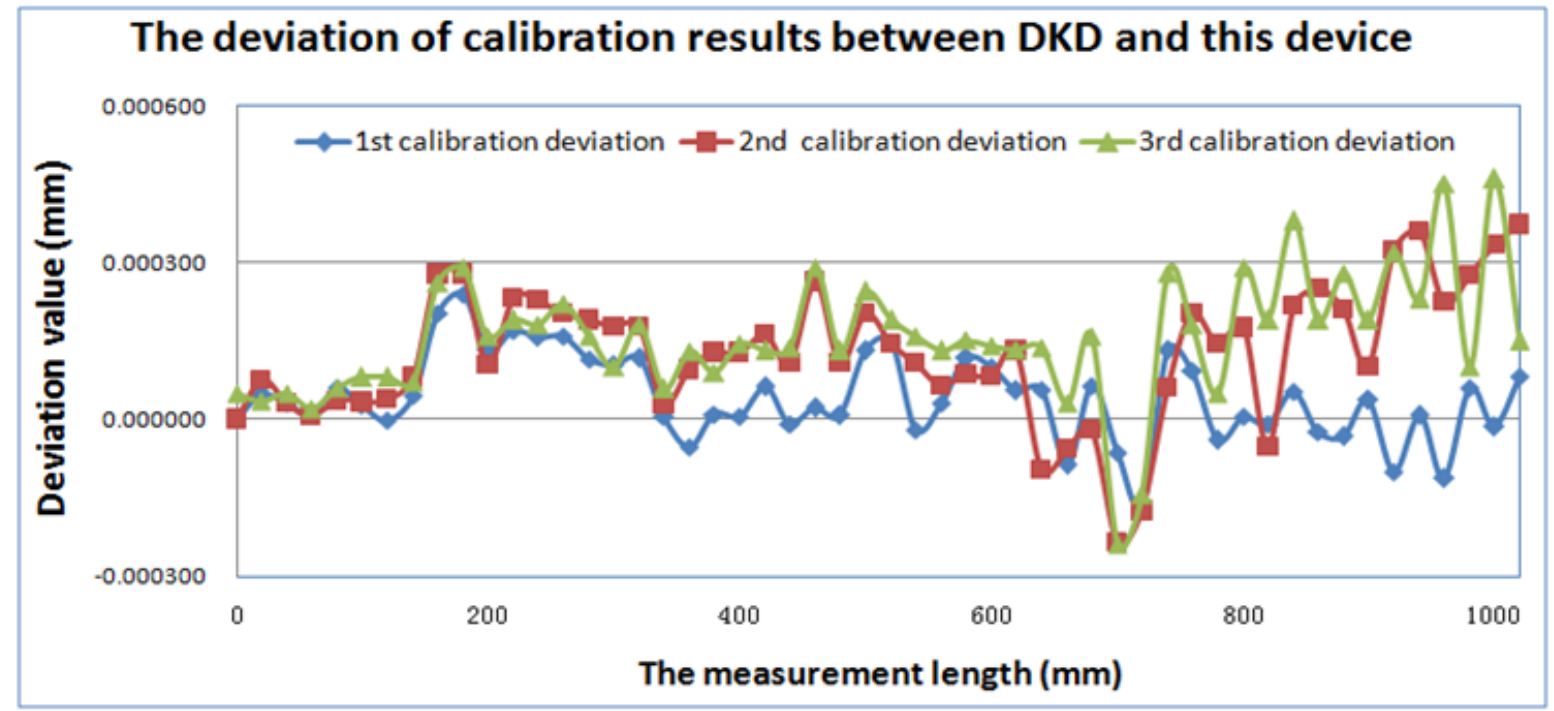

Figure 6. The variation trend of differences between Deutscher Kalibrierdienst (DKD) data and our device with measurement length.

In order to verify the measurement accuracy of this device, a second-grade standard gauge block of $500 \mathrm{~mm}$ was repeatedly calibrated 10 times. The deviation between the measurement results of this device and the nominal value of the gauge block is shown in Figure 7. 


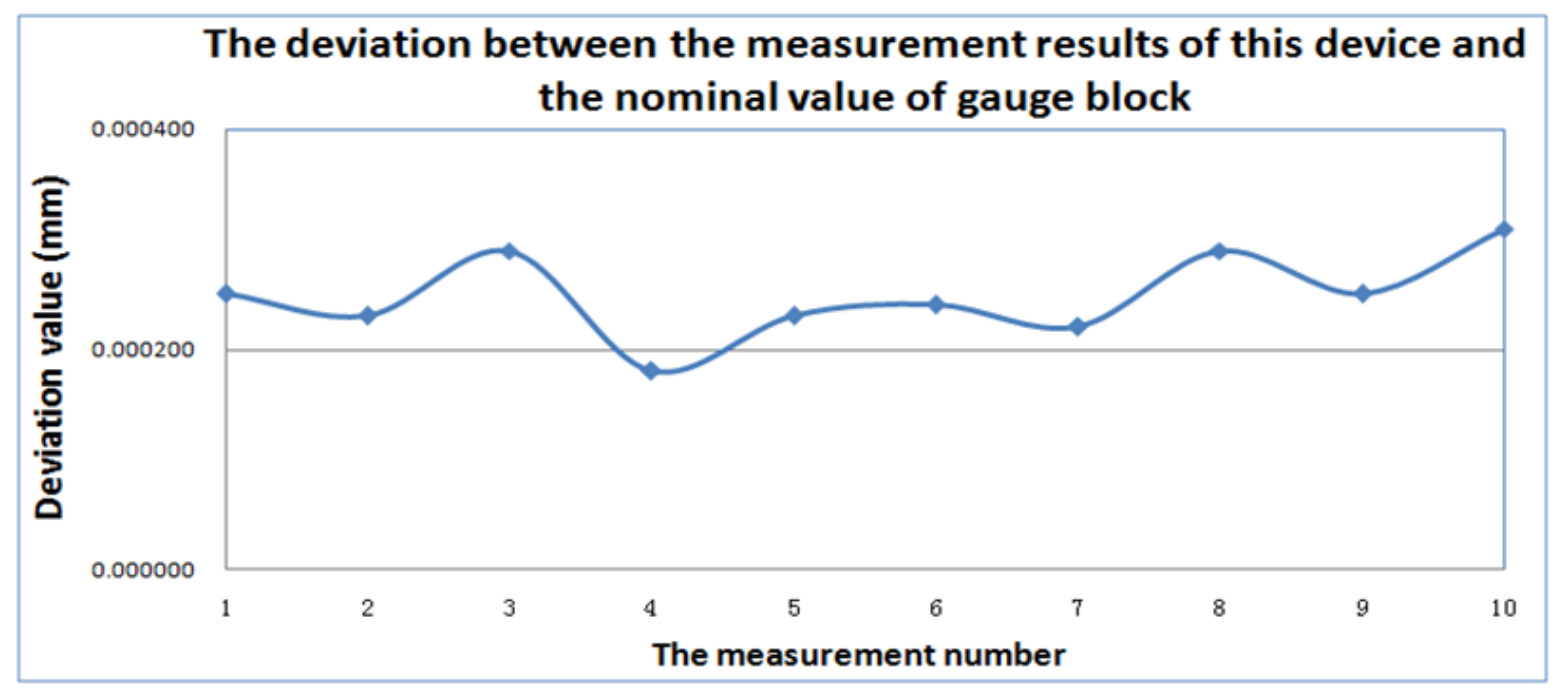

Figure 7. The trend chart of deviation of measurement result of this device from nominal value.

\section{Measurement Uncertainty}

From this device, we can evaluate the uncertainty in measurement in accordance with the GUM (ISO, "Guide to the Expression of Uncertainty in Measurement," Switzerland, 1993, corrected and reprinted 1995). The calibration value is obtained by Equation $(9)[8,18]$.

$$
L_{\text {stepgage }}=L_{\text {measured }}-L_{\text {measured }} \alpha_{\text {stepgage }} \Delta t_{\text {stepgage }}+\delta_{\text {Astepgage }}+\delta_{\text {Alaser }}+\delta_{\text {probing }}+\delta_{\text {sphere }}
$$

where:

$L_{\text {stepgage }}$ : the measured distance of the step gauge at the reference temperature of $20^{\circ} \mathrm{C}$.

$L_{\text {measured }}$ : the distance of the step gauge from the calculated measurement value of SMLI.

$\alpha_{\text {stepgage }}$ : the thermal expansion coefficient of the step gauge.

$\Delta t_{\text {stepgage: }}$ the difference between the step gauge temperature and the reference temperature of $20{ }^{\circ} \mathrm{C}$.

$\delta_{\text {Astepgage }}:$ the uncertainty of the step gauge alignment.

$\delta_{\text {Alaser }}$ : the uncertainty of the laser alignment.

$\delta_{\text {Probing }}:$ the reproducibility of the probing.

$\delta_{\text {sphere }}$ : the uncertainty of the standard sphere calibration.

The uncertainty of the step gauge calibration is calculated by Equation (10).

$$
\begin{aligned}
u\left(L_{\text {stepgage }}\right)^{2}= & u\left(L_{\text {measured }}\right)^{2}+L^{2}{ }_{\text {Nom. }} \times u\left(\alpha_{\text {stepgage }}\right)^{2} \times \Delta t^{2}{ }_{\text {stepgage }} \\
& +L^{2} \text { Nom. } \times \alpha^{2} \text { stepgage } \times u\left(\Delta t_{\text {stepgage }}\right)^{2}+u\left(\delta_{\text {Astepgage }}\right)^{2}+u\left(\delta_{\text {Alaser }}\right)^{2} \\
& +u\left(\delta_{\text {Probing }}\right)^{2}+u\left(\delta_{\text {sphere }}\right)^{2} .
\end{aligned}
$$

Table 2 shows the uncertainty components in the step gauge calibration. 
Table 2. Uncertainty budget in step gauge calibration.

\begin{tabular}{ccccc}
\hline No. & Sources of Nncertainty & Magnitude & Type & Uncertainty \\
\hline 1 & Probing repeatability & $0.034 \mu \mathrm{m}$ & $\mathrm{A}$ & $0.034 \mu \mathrm{m}$ \\
\hline 2 & Calibration of probe & $0.030 \mu \mathrm{m}$ & $\mathrm{B}$ & $0.030 \mu \mathrm{m}$ \\
\hline 3 & Uncertainty of standard sphere & $0.030 \mu \mathrm{m}$ & $\mathrm{B}$ & $0.030 \mu \mathrm{m}$ \\
\hline 4 & Temperature measurement & $5 \mathrm{mK}$ & $\mathrm{B}$ & $0.143 \mathrm{~L} \mu \mathrm{m}$ \\
\hline 5 & Temperature distribution & $10 \mathrm{mK}$ & $\mathrm{A}$ & $0.286 \mathrm{~L} \mu \mathrm{m}$ \\
\hline 6 & Wavelength (frequency) & $1.5 \mathrm{MHz}$ & $\mathrm{B}$ & $0.002 \mathrm{~L} \mu \mathrm{m}$ \\
\hline 7 & Wavelength (temperature) & $95 \mathrm{mK}$ & A & $0.053 \mathrm{~L} \mu \mathrm{m}$ \\
\hline 8 & Wavelength (air pressure) & $53 \mathrm{~Pa}$ & $\mathrm{~A}$ & $0.081 \mathrm{~L} \mu \mathrm{m}$ \\
\hline 9 & Wavelength (humidity) & $0.64 \%$ & $\mathrm{~A}$ & $0.008 \mathrm{~L} \mu \mathrm{m}$ \\
\hline 10 & Wavelength (CO2) & $50 \mathrm{ppm}$ & $\mathrm{B}$ & $0.004 \mathrm{~L} \mu \mathrm{m}$ \\
\hline 11 & Thermal expansion coefficient & $1.0 \times 10^{-6} / \mathrm{K}$ & $\mathrm{B}$ & $0.365 \mathrm{~L} \mu \mathrm{m}$ \\
\hline 12 & Error of cosine (step gauge) & $0.1 \mathrm{~mm} / 1020 \mathrm{~mm}$ & $\mathrm{~B}$ & $0.005 \mathrm{~L} \mu \mathrm{m}$ \\
\hline 13 & Error of cosine (laser) & $0.1 \mathrm{~mm} / 1020 \mathrm{~mm}$ & $\mathrm{~B}$ & $0.005 \mathrm{~L} \mu \mathrm{m}$ \\
\hline
\end{tabular}

In Table 2, 1-3 are the independent sources of uncertainty, and 4-13 are dependent on thermal expansion uncertainties and have been converted to the length $\mathrm{L}$.

Then, the uncertainty in measurement of the step gauge calibration using our instrument is as follows.

$$
U=\left(k \times \sqrt{0.054^{2}+(0.50 L)^{2}}\right) \mu \mathrm{m} ; L: \mathrm{m} ; k: \text { coverage factor. }
$$

\section{Conclusions}

In order to achieve the high calibration accuracy of the step gauge, we proposed acomputational model of step gauge calibration based on SMLI technology, completed the corresponding mathematical modeling and simulation, and established a set of calibration device. We also carried out experimental verification and uncertainty analysis.

From the measurement results, we find that, although the measurement repeatability of this calibration device is stable over a short distance, it has a divergence trend over a long distance. Although the deviation of the measurement results is in accordance with the uncertainty analysis conclusion claimed by the device, the specific causes of this phenomenon will be further analyzed and studied.

In the future, we will further reduce the measurement uncertainty and improve the calibration accuracy according to the error source. It is hoped that this paper will provide a new measurement method reference for related researchers.

Author Contributions: Conceptualization, G.R. and X.Q.; data curation, X.C.; methodology, G.R.; software, G.R.; writing - original draft, G.R. All authors have read and agreed to the published version of the manuscript.

Funding: This research was funded by the National Key Research and Development Program of China, grant number: 2018YFF0212702.

Acknowledgments: This study was supported by the National Key Research and Development Program of China (Grant No.: 2018YFF0212702). The authors would like to thank the other members of the research team for their contributions to this study.

Conflicts of Interest: The authors declare no conflict of interest. 


\section{References}

1. Jusko, O.; Brown, N.; Thalmann, R.; Reyes, E.A.; Phillips, S.; Eom, C.I.; Shaoxi, S.; Takatsuji, T.; Prieto, E. CCL-K5: CMM 1D: Step gauge and ball bars: Final report. Metrologia 2006, 43, 04006. [CrossRef]

2. $\quad$ Eom, T.; Sitian, G.; Wong, S.Y.; Chaudhary, K.P.; Drijarkara, A.P.; Howick, E.; Tonmeanwai, A.; Pan, S.-P.; Takatsuji, T.; Cox, P.; et al. Final report on APMP Regional Comparison APMP.L-K5: Calibration of step gauge. Metrologia 2012, 49, 04007. [CrossRef]

3. Prieto, E.; Brown, N.; Lassila, A.; Lewis, A.; Matus, M.; Vailleau, G.; De Chiffre, L.; Kotte, G.W.J.L.; Frennberg, M.; McQuoid, H.; et al. Final report on inter-RMO Key Comparison EUROMET.L-K5.2004: Calibration of a step gauge. Metrologia 2012, 49, 04008. [CrossRef]

4. Abe, M.; Drijarkara, A.P.; Babu, V. Bi-lateral comparison APMP.L-K5.2006.1—calibration of step gauge. Metrologia 2017, 54, 4006. [CrossRef]

5. Hemming, B.; Esala, V.-P.; Laukkanen, P.; Rantanen, A.; Viitala, R.; Widmaier, T.; Kuosmanen, P.; Lassila, A. Interferometric step gauge for CMM verification. Meas. Sci. Technol. 2018, 29, 074012. [CrossRef]

6. A Kruger, O. High-accuracy interferometric measurements of flatness and parallelism of a step gauge. Metrologia 2001, 38, 237-240. [CrossRef]

7. Osawa, S.; Takatsuji, T.; Noguchi, H.; Kurosawa, T. Development of a ball step-gauge and an interferometric stepper used for ball-plate calibration. Precis. Eng. 2002, 26, 214-221. [CrossRef]

8. Osawa, S.; Takatsuji, T.; Kurosawa, T. STEP-gauge calibration using an interferometric coordinate measuring machine and the uncertainty. In Proceedings of the XVII imeko World Congress, Dubrovnik, Croatia, 22-27 June 2003.

9. Stoup, J.; Faust, B. Measuring Step Gauges Using the NIST M48 CMM. NCSLI Meas. 2011, 6, 66-73. [CrossRef]

10. Byman, V.; Jaakkola, T.; Palosuo, I.; Lassila, A. High accuracy step gauge interferometer. Meas. Sci. Technol. 2018, 29, 054003. [CrossRef]

11. Weichert, C.; Bütefisch, S.; Köning, R.; Flügge, J. Integration of a step gauge measurement capability at the PTB Nanometer Comparator-Concept and preliminary tests. In Proceedings of the Conference "MacroScale 2017-Recent Developments in Traceable Dimensional Measurements", VTT MIKES Espoo, Finnland, 17-19 October 2017. [CrossRef]

12. Ren, G.; Qu, X.; Ding, S. A Real-Time Measurement Method of Air Refractive Index Based on Special Material Etalon. Appl. Sci. 2018, 8, 2325. [CrossRef]

13. Guo-Ying, R.; Wei-Nong, W.; Zi-Jun, W. Uncertainty Analysis for Measurement of Step Gauges Based on Coordinate Measuring Machine. Acta Metrol. Sin. 2008, 29 (Suppl. S1), 151-153.

14. Bönsch, G.; Potulski, E. Measurement of the refractive index of air and comparison with modified Edlen's formula. Metrologia 1998, 35, 133-139. [CrossRef]

15. Garcia-Murillo, M.A.; Sanchez-Alonso, R.E.; Gallardo-Alvarado, J. Kinematics and Dynamics of a Translational Parallel Robot Based on Planar Mechanisms. Machines 2016, 4, 22. [CrossRef]

16. Zhang, X.; Dong, Y.; Zhang, L. kinematics modeling and simulation of a five-bar Cabot by using closed loop vector method. Control Theory Appl. 2006, 25. [CrossRef]

17. Buschhaus, A.; Blank, A.; Franke, J. Vector based closed-loop control methodology for industrial robots. In Proceedings of the 2015 International Conference on Advanced Robotics (ICAR), Istanbul, Turkey, 27-31 July 2015; pp. 452-458.

18. BIPM; IEC; IFCC; ISO; IUPAC; IUPAP; OIML. Evaluation of measurement data - Guide to the expression of uncertainty in measurement. Int. Organ. Stand. Geneva ISBN 2008, 50, 134.

(C) 2020 by the authors. Licensee MDPI, Basel, Switzerland. This article is an open access article distributed under the terms and conditions of the Creative Commons Attribution (CC BY) license (http://creativecommons.org/licenses/by/4.0/). 